\title{
Microstructure and Properties of Diffusion Bonded Mg/Al Joints
}

\author{
Yunlong Ding ${ }^{1,2, a}$, Dongying Ju $\mathrm{u}^{1,2, \mathrm{~b},{ }^{*}}$
}

${ }^{1}$ School of Mechanical Engineering and Automation, University of Science and Technology Liaoning, No.185 Qianshan Mid-Road, Anshan, Liaoning,114051, China

${ }^{2}$ Department of Material Science and Engineering, Saitama Institute of Technology, Fusaiji1690, Fukaya, Saitama 369-0293, Japan

aemail:yunlong.ding@yahoo.com, bemail:dyju@sit.ac.jp

*corresponding author, Tel: 8148-5856826, Fax: 81-48-5855928.

Keywords: magnesium alloy AZ31; aluminum alloy 6061; diffusion bonding; annealing; mechanical property; interface; crystal structure

\begin{abstract}
In this study, magnesium alloy AZ31 was successfully welded with aluminum alloy 6061 by diffusion bonding method. Annealing process was applied to refine the microstructure and improve the mechanical properties of the joints. It has been found that the width of diffusion layers increases with increasing annealing temperature. Elemental distribution becomes more uniform by annealing. Intermetallic compounds of $\mathrm{Al}_{3} \mathrm{Mg}_{2}$ and $\mathrm{Al}_{12} \mathrm{Mg}_{17}$ were observed in the diffusion layers and their crystal structures are respectively face-centered cubic (fcc) and body-centered cubic (bcc). It was also found that annealing at $250^{\circ} \mathrm{C}$ results in the highest tensile strength of joints.
\end{abstract}

\section{Introduction}

As an extremely light metal, magnesium and its alloys have received growing attention due to their low densities, high specific strengths, excellent casting ability, outstanding hot formability, good electromagnetic interference shielding and recycle ability, but it is easily corroded[1-5]. While aluminum and its alloys have good corrosion resistance and they are also widely used for their attractive mechanical and metallurgical properties, such as high specific strength, good workability, high thermal and electrical conductivity [6-9]. With the growing emphasis on energy economy and environmental concerns, $\mathrm{Mg}$ alloys have become a favored choice in the automobile field. If aluminum alloys and magnesium alloy can be bonded and form a kind of composite material, not only would the flexibility and availability of the material be substantially improved, but also the weight and cost would be reduced. Presently, there are many studies on this topic. Many welding methods have been applied to join $\mathrm{Mg}$ alloys and $\mathrm{Al}$ alloys. However, no matter which technique is used, brittle and hard intermetallic compounds form in the joints. This weakens the tensile strength of the joints. As was previously reported elsewhere, the tensile strength of bonded specimens was only $37 \mathrm{MPa}[10]$. Annealing can soften and restore the ductility and formability of materials [11]. What's more, it can transform the structure of crystals and eliminate defects in microstructures, thereby reducing the brittleness and improving the mechanical characteristics of materials. In this study, in order to investigate these effects, annealing treatments were applied at different temperatures. In addition, the microstructures and their properties were evaluated. Based on this work, applications of the composite material formed by diffusion bonding of aluminum alloy and magnesium alloy could be extensive. The composite materials will lead to light-weight components, which will in turn lead to decreased depletion of resources and reduced energy usage, which can help mitigate environmental pollution.

\section{Experimental}

The first step in the experimental procedure was to cut AZ31B magnesium alloy sheets and 6061 aluminum alloy sheets according to the dimensions shown in Fig. 1. 


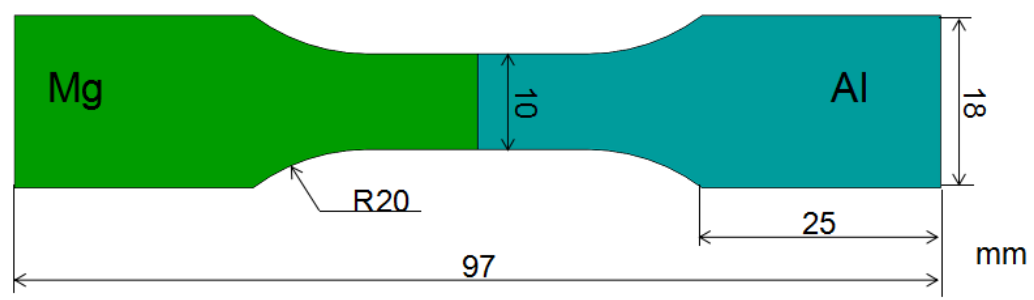

Fig.1 Dimensions of specimen

The oxide layers on the surface of the substrate were then polished with abrasive papers and the ground samples were wiped with acetone before joining. According to the $\mathrm{Mg}-\mathrm{Al}$ phase diagram, the joining temperature was chosen as $440^{\circ} \mathrm{C}$. Specimens were successfully joined with a method called vacuum diffusion bonding under the protection of argon gas. In order to refine microstructures and improve the properties of the bonding layers, annealing treatment was carried out. Samples were annealed at the temperatures of 200,250 and $300^{\circ} \mathrm{C}$, holding time is $1 \mathrm{~h}$, which is based on previous research [12], then cooled down to room temperature in electric furnace [13].

For the purpose of studying microstructures and properties of interfaces, a series of specimens annealed at different conditions were cut across the diffusion zone. The cut sections were ground and polished. The microstructures and elemental distribution of the joints were then studied using SEM, TEM and EPMA. The tensile strength was also measured.

\section{Results and Discussion}

The microstructure was observed with SEM and shown in Fig.2 to Fig.5. The diffusion layers are clearly distinguishable in SEM micrographs and their width increases with increasing annealing temperature. This is because the diffusion rate increases with increasing temperatures. What's more, it can be depicted as that the microstructure after annealing at $250^{\circ} \mathrm{C}$ is the most uniform than others.

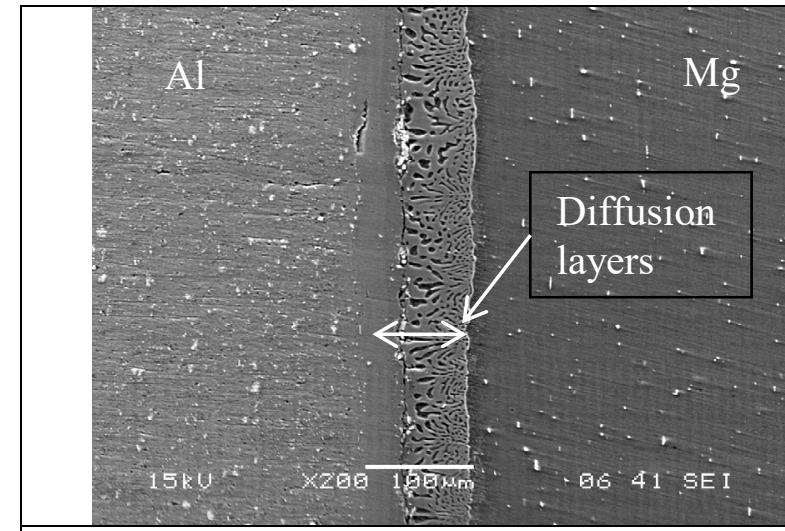

Fig.2 SEM micrograph, without annealing

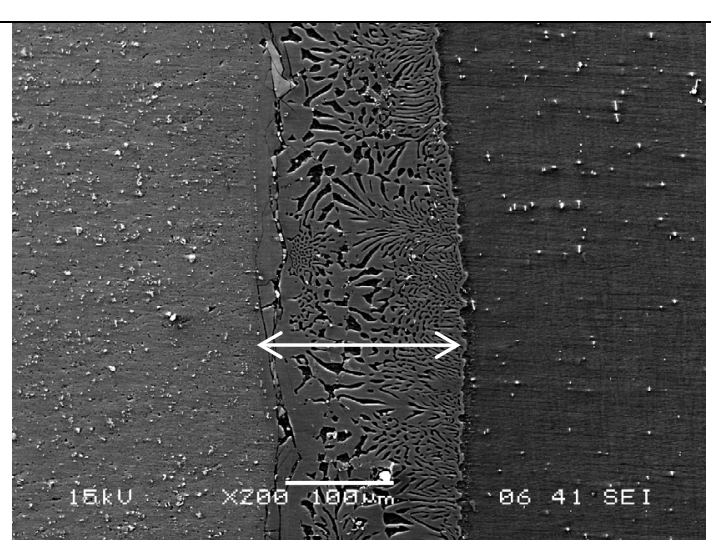

Fig.3 SEM micrograph, with annealing at $200^{\circ} \mathrm{C}$ 


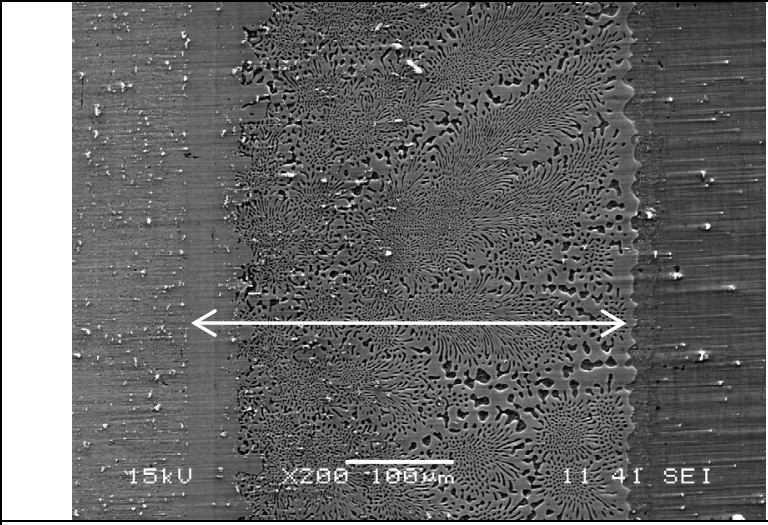

Fig.4 SEM micrograph, with annealing at $250^{\circ} \mathrm{C}$

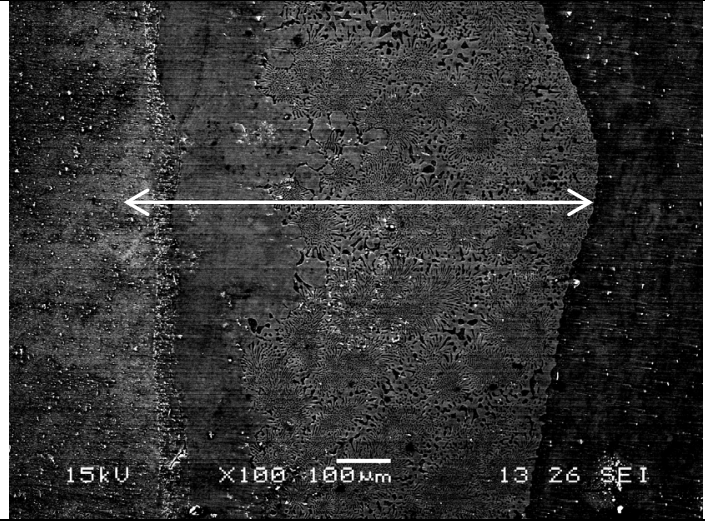

Fig.5 SEM micrograph, with annealing at $300^{\circ} \mathrm{C}$

After the investigation performed by TEM, the results were shown in Fig.6 and Fig.7. According to the scale in Fig.6, and the measurement of the distance to the center, the actual interplanar spacing was calculated, after compared with the database, the conclusion was obtained that $d_{1}$ is $0.283 \mathrm{~nm}, \mathrm{~d}_{2}$ is $0.187 \mathrm{~nm}$. The results indicated the (771) and (1511) planes of $\mathrm{Al}_{3} \mathrm{Mg}_{2}$, whose crystal structure is face-centered cubic (fcc).

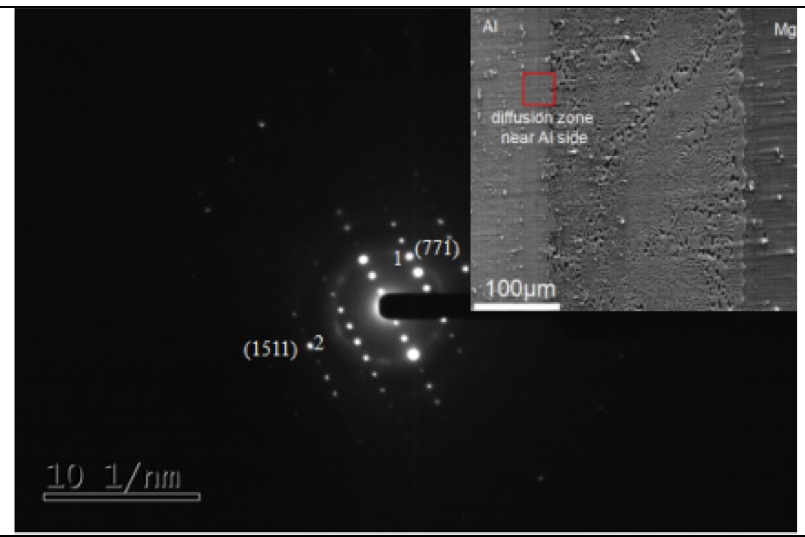

Fig.6 Diffraction pattern of diffusion layer near Al alloy

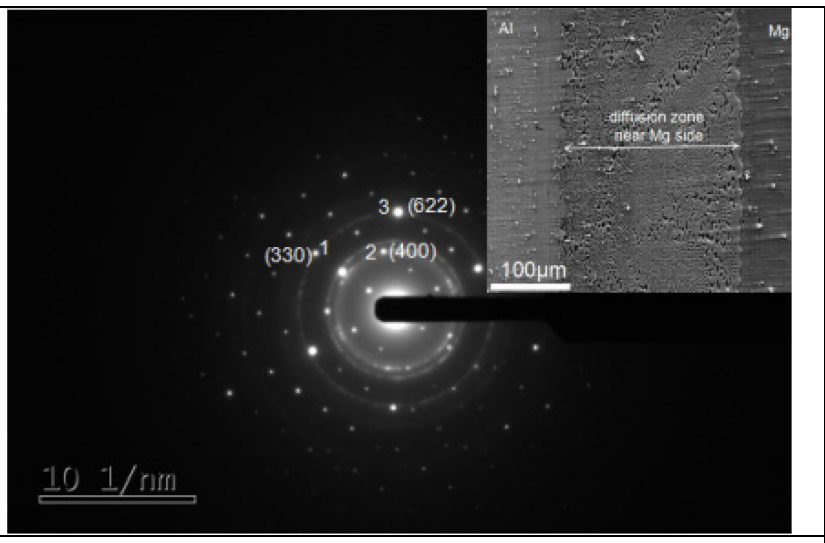

Fig.7 Micrograph of diffraction spots on diffusion layer near Mg alloy

Based on the scale in Fig.7 and the distance from the diffraction spots to the center, interplanar spacing can be calculated. After referring to the database, the planes index can be obtained [14]. The interplanar spacing d1, d2, d3 are respectively $0.2480 \mathrm{~nm}, 0.2640 \mathrm{~nm}, 0.1600 \mathrm{~nm}$. So the corresponding plane index are (330), (400) and (622) of $\mathrm{Al}_{12} \mathrm{Mg}_{17}$. And the crystal structure is body-centered cubic (bcc).

The results of elemental analysis with EPMA are shown in Fig.8. Elemental distribution of specimens annealed at $200^{\circ} \mathrm{C}, 250^{\circ} \mathrm{C}, 300^{\circ} \mathrm{C}$, are shown in (b), (c) and (d) respectively. While (a) corresponds to the condition without annealing. Clearly, the diffusion layers become wide when the heat treatment temperature is increased. The reason for this variation in the width of diffusion layers and element abundances is the diversity of annealing temperature. Elemental diffusion rates increase with increasing temperature, and diffusion layer is therefore the widest when the samples are annealed at $300^{\circ} \mathrm{C}$. However, elemental distribution is the most uniform in the condition of $250^{\circ} \mathrm{C}$. 


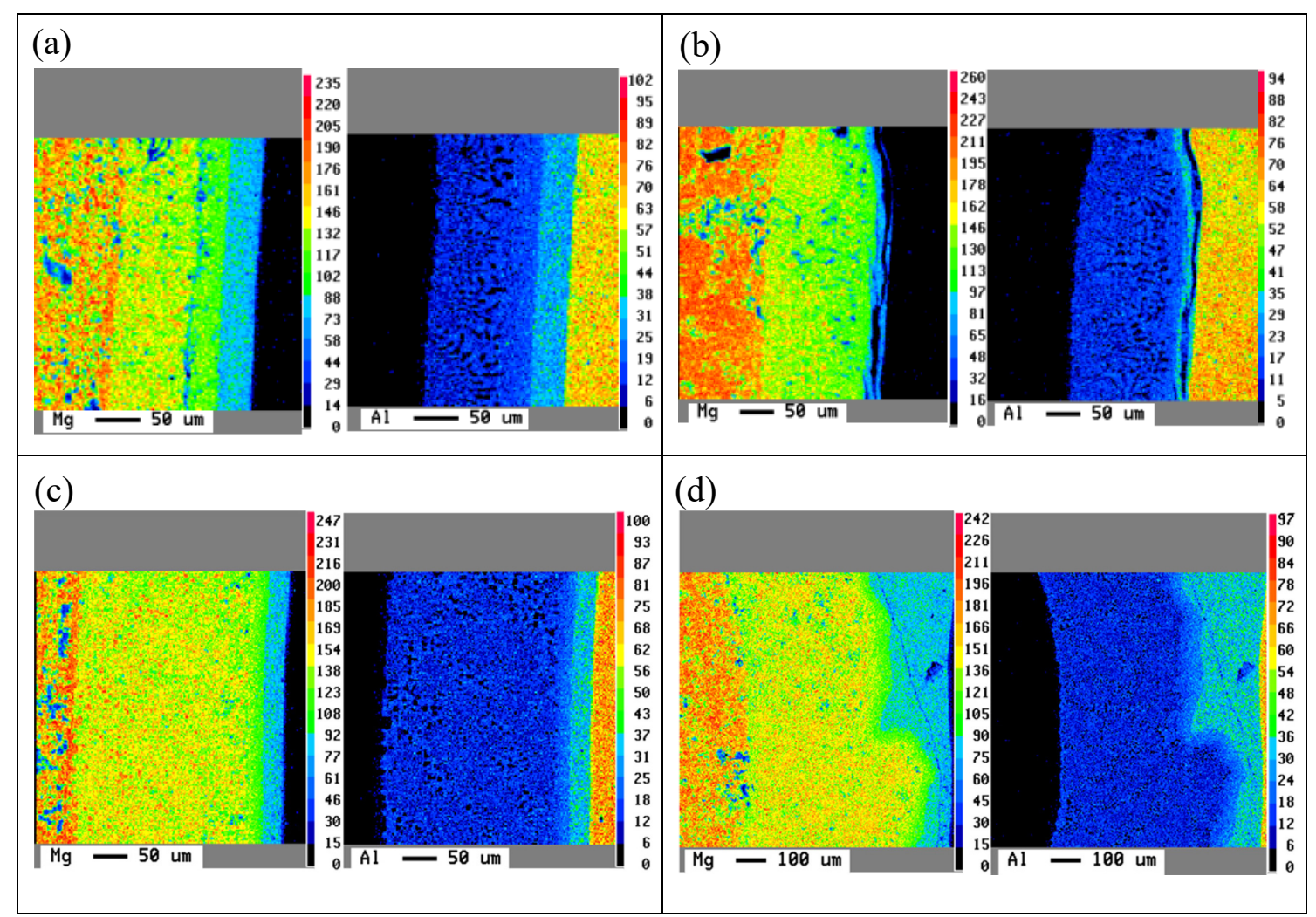

Fig.8 Result of elemental analysis; (a) without annealing, (b) annealing at $200^{\circ} \mathrm{C}$, (c) annealing at $250^{\circ} \mathrm{C}$ and (d) annealing at $300^{\circ} \mathrm{C}$

The results of tensile strength are shown in Fig.9. The tensile strength is the highest when the annealing temperature is $250^{\circ} \mathrm{C}$, of about $45 \mathrm{MPa}$. When the samples are annealed at 200 and $300^{\circ} \mathrm{C}$, the values of tensile strength are approximately 30 and $28 \mathrm{MPa}$ respectively. Untreated specimens exhibit a tensile strength of $29 \mathrm{MPa}$. In this work, the application of annealing treatment results in a higher tensile strength.

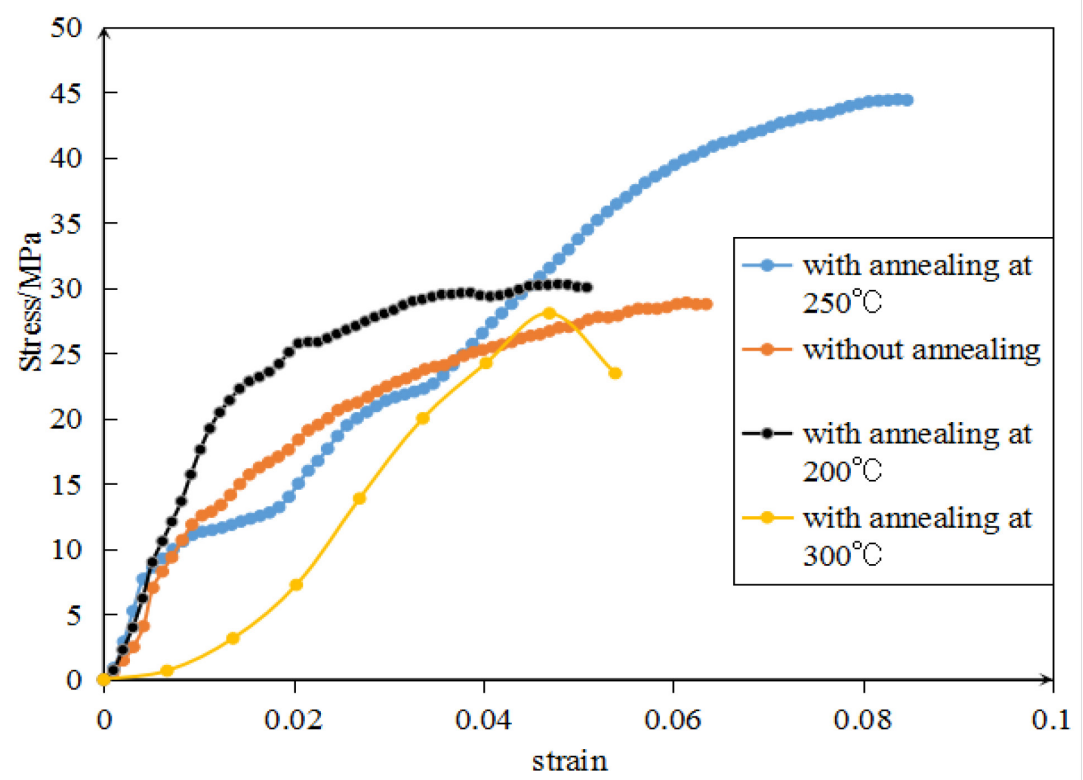

Fig.9 Stress-strain graph 


\section{Summary}

Annealing is found to refine the microstructure of the $\mathrm{Al} / \mathrm{Mg}$ joints, resulting better tensile strength. The following conclusions can be drawn:

1. The width of the diffusion layers increases with increasing annealing temperature. The elemental distribution of specimens with annealing were more uniform than that without annealing. When annealed at $250^{\circ} \mathrm{C}$, elemental distribution is the most uniform.

2. The intermetallic compounds in diffusion layers are $\mathrm{Al}_{3} \mathrm{Mg}_{2}$ and $\mathrm{Al}_{12} \mathrm{Mg}_{17}$, and crystal structure are respectively face-centered cubic (fcc) and body-centered cubic (bcc).

3. This method is not only useful for diffusion bonded joints of MgAZ31 and Al 6061, but also can be applicable for other $\mathrm{Mg} / \mathrm{Al}$ joints, because the conditions are depended on the phase graph of $\mathrm{Mg} / \mathrm{Al}$ alloy.

4. Annealing can refine microstructure and improve mechanical property. According to $\mathrm{Mg}-\mathrm{Al}$ phase graph, when annealing temperature is near $300^{\circ} \mathrm{C}$, a new brittle and hard intermetallic compounds will generate, tensile strength of welded specimens will be decreased, compared with other conditions, after being annealed at $250^{\circ} \mathrm{C}$, the tensile strength turns to be the strongest. Therefore, when holding time is 1 hour, $250^{\circ} \mathrm{C}$ is the most appropriate annealing temperature.

\section{References}

[1] LAKSHMINARAYANAN A K, ANNAMALAI V E. Fabrication and performance evaluation of dissimilar magnesium-aluminium alloy multi-seam friction stir clad joints, J. Transactions of Nonferrous Metals Society of China. 27 (2017) 25-35.

[2] Yun-long DING, Jian-gang WANG, Ming ZHAO, Dong-ying JU. Effect of annealing temperature on joints of diffusion bonded Mg/Al alloys, J. Trans. Nonferrous Met. Soc. China. 28 (2018) 251258.

[3] Liming Liu, Daxin Ren, and Fei Liu. A Review of Dissimilar Welding Techniques for Magnesium Alloys to Aluminum Alloys, J. Materials (Basel). 7(5) (2014) 3735 - 3757.

[4] Haferkamp H., Niemeyer M., Dilthey U., Trager G. Laser and electron beam welding of magnesium materials. J. Weld. Cutt. 52 (2000) 178-180.

[5] Sanders P.G., Keske J.S., Leong K.H., Kornecki G. High power Nd:YAG and $\mathrm{CO}_{2}$ laser welding of magnesium. J. Laser. Appl. 11 (1999) 96-103.

[6] Jeal N. High-performance magnesium. J. Adv. Mater. Process. 163 (2005) 65-67.

[7] Cam G., Kocak M. Progress in joining of advanced materials. J. Int. Mater. Rev. 43 (1998) 1-44.

[8] Schubert E., Klassen M., Zerner I., Walz C., Sepold G. Light-weight structures produced by laser beam joining for future applications in automobile and aerospace industry. J. Mater. Process. Technol. 2001; 115:2-8.

[9] Lanza M., Lauro A., Scanavino S. Fabrication and weldability in structures. J. AL Alumin. Alloys. 2001; 13:80-86.

[10] SHANG Jing, WANG Ke-hong, ZHOU Qi, ZHANG De-ku, HUANG Jun, GE Jia-qi. Effect of joining temperature on micro-structures and properties of diffusion bonded $\mathrm{Mg} / \mathrm{Al}$ joints. J. Transactions of Nonferrous Metals Society of China. 22 (2012) 1961-1966. 
[11] SUN Hong-fei, CHAO Hong-ying, WANG Er-de. Microstructure stability of cold drawn AZ31 magnesium alloy during annealing Process. J. Transactions of Nonferrous Metals Society of China. 21 (2011) s215-s221.

[12] Ming Zhao. Study on bonding mechanism and properties evaluation in diffusion bonding of magnesium/aluminum alloys. Saitama Institute of Technology, Japan, 2014.

[13] Yun-long DING, Dong-ying JU. Finite Element Analysis of Residual Stress in the Diffusion Zone of Mg/Al Alloys. J. Advances in Materials Science and Engineering. Volume 2018, Article ID 1209849,8 pages.

[14] Yun-long DING. Study on Residual Stress and Mechanical Behavior of intermetallic Compound Layer in Diffusion Bonding of Mg/Al Alloy. Saitama Institute of Technology, Japan, 2018, Pp.45-48. 